\title{
The Research of SUV Dynamic Rollover Warning System based on Hardware-in-the-loop
}

\author{
Lixin Song ${ }^{1}$, Wenham Zhang ${ }^{2, b}$ \\ ${ }^{1}$ College of Physics and Electronic Engineering, Hubei University of Arts and Science, XiangYang, \\ 441053, China \\ ${ }^{2}$ Institute of Information Engineering, Chinese Academy of Sciences, Beijing, 100093, China \\ asonglixin66@qq.com, bzhangwh909@163.com
}

Keywords: differential braking control, time to rollover, hardware-in-the-loop, rollover warning

Abstract. This paper presents a control system based on rollover warning for Sport Utility Vehicles (SUVs). To get accurate information of vehicle rollover timely, a four degree of freedom model is established, the dynamic rollover warning algorithm is studied and the hardware systems about the algorithm are realized. Then a differential braking will be used to prevent the rollover. The hardware-in-the-loop real-time simulations are conducted on the vehicle simulator, the Double Lane Change tests are applied to examine the control performance of the dynamic rollover warning system.

\section{Introduction}

The Sport Utility Vehicles (SUVs) usually have much higher center of gravities and lower threshold of rollover stability, so their rollover stability causes great attention from the scholars in the world, they have done much research on vehicle rollover and its control methods[1,2]. However, their methods can only prevent the rollovers in the driving [3, 4], they do not provide warning information timely to the driver or controllers in advance. The papers [5]--[7] studied the rollover forecasts and warning which timely calculate the time to rollover according to lateral load transfer ratio (LTR). Although these warning systems can warn to the driver ahead, but how to act to prevent rollover need the driver to judge by his experience which has much occasionally. So, in order to advance the vehicle active safety and reduce the driver burden, the corresponding safety control system should be designed above the rollover warning. This paper studies the decisions about the time to rollover and the control effects using hardware-in-the-loop real-time simulations reconstructed in Lab View and Car Sim software packages. A online anti-rollover warning test platform is constructed with the controller, the SUV and the hardware warning parts by the interfaces between hardware and software. The all scenarios are showed in the vehicle simulator to verify the warning algorithm and control results.

\section{The Rollover Dynamic Model}

In order to provide real environment and timely warning, this paper use the simplified rollover dynamic model shown in Figure.1. It is assumed that the vehicle dynamics characters are symmetric about $X$ axis, the motion of the model include lateral motion in $X$ axis, yaw motion circling $Z$ axis(which is vertical with $X Y$ plane) and the rollover motion circling $X$ axis. In Fig.1, the front wheel steering angle is $\delta_{f}$, vehicle body roll angle is $\varphi$, the rollover dynamic equation of this SUV model is obtained as follow:

The force balance equation in lateral direction ( $Y$ axis) is given by:

$\mathrm{m}\left(\dot{\mathrm{V}}+\mathrm{U}_{\gamma}\right)-\mathrm{m}_{\mathrm{s}} \mathrm{h} \ddot{\varphi}=\mathrm{F}_{\mathrm{yfl}}+\mathrm{F}_{\mathrm{yfr}}+\mathrm{F}_{\mathrm{yrl}}+\mathrm{F}_{\mathrm{yrr}}$

The torque balance equation in yaw direction (circling $Z$ axis) is given by:

$\mathrm{I}_{\mathrm{z}} \dot{\gamma}=\mathrm{I}_{\mathrm{f}}\left(\mathrm{F}_{\mathrm{yfl}}+\mathrm{F}_{\mathrm{yfr}}\right)-\mathrm{I}_{\mathrm{r}}\left(\mathrm{F}_{\mathrm{yrl}}+\mathrm{F}_{\mathrm{yrr}}\right)+\Delta \mathrm{M}$ 


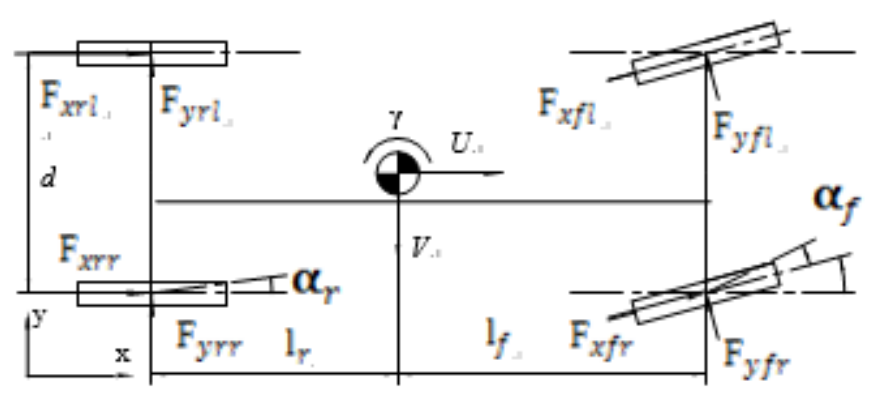

(a) Overlook view of a SUV

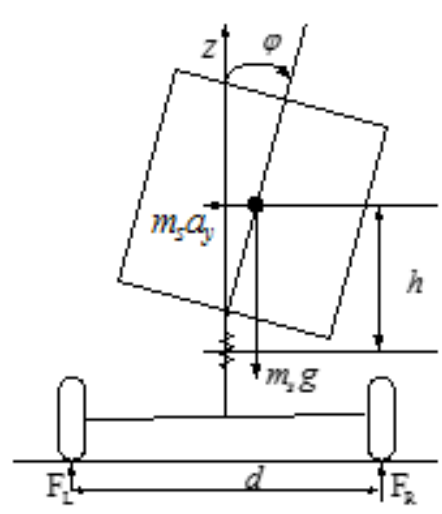

(b) Rollover plane model

Fig. 1 The rollover dynamic model

The torque balance equation in circling $X$ axis is given by:

$$
\mathrm{I}_{\mathrm{x}} \ddot{\varphi}=\mathrm{m}_{\mathrm{s}} \mathrm{gh} \varphi-\mathrm{c}_{\varphi} \dot{\varphi}-\mathrm{k}_{\varphi} \varphi-\mathrm{m}_{\mathrm{s}} \mathrm{h}^{2} \ddot{\varphi}+\mathrm{m}_{\mathrm{s}} \mathrm{ha}_{\mathrm{y}}
$$

In (1),(2) and (3), $m$ is Mass of the vehicle, $m_{s}$ is Sprung mass, $U / V$ is Longitudinal velocity/Lateral velocity of Central Gravity(CG), $\quad \gamma / \dot{\gamma}$ is Yaw rate/Yaw angular acceleration, $c_{f} / c_{r}$ is Front cornering stiffness/Rear cornering stiffness, $\mathrm{F}_{x f l} / F_{x f r}$ is Longitudinal force of front-left tire/Longitudinal force of front-right tire, $\mathrm{F}_{\mathrm{yfl}} / F_{y f r}$ is Lateral force of front-left tire/Lateral force of front-right tire, $\mathrm{F}_{x r l} / F_{x r r}$ is Longitudinal force of rear-left tire/Longitudinal force of rear-right tire, $\mathrm{F}_{y r l} / F_{y r r}$ is Lateral force of rear-left tire/Lateral force of rear-right tire, $I_{x} / I_{z}$ is Moment of inertia about $\mathrm{X}$ axis/Z axis, $l_{f} / l_{r}$ is Distance from CG to front axle/Distance from CG to rear axle, $\mathrm{d}$ is vehicle Axle tread, $\dot{\varphi} / \ddot{\varphi}$ is Vehicle rollover angle velocity/vehicle rollover angle acceleration, $\mathrm{k}_{\varphi}$ is Suspension roll stiffness, $\mathrm{c}_{\varphi}$ is Suspension roll damp, $\alpha_{f}$ is Front tire slip angle, $\mathrm{h}$ is roll arm length, $\mathrm{F}_{\mathrm{L}} / \mathrm{F}_{\mathrm{R}}$ is Left vertical load/Right vertical load, $\mathrm{a}_{\mathrm{y}}$ is the vehicle lateral acceleration, $\Delta M$ is the required compensated moment.

Considering the roll camber and the roll steer, the front/rear tire sideslip angle can be obtained as [6]:

$$
\begin{aligned}
& \alpha_{\mathrm{f}}=-\frac{\mathrm{v}+\mathrm{l}_{\mathrm{f} Y}}{\mathrm{u}}+\delta_{\mathrm{f}}+\mathrm{k}_{\mathrm{f}} \varphi \\
& \alpha_{\mathrm{r}}=-\frac{\mathrm{v}-\mathrm{l}_{\mathrm{r}} \gamma}{\mathrm{u}}+\mathrm{k}_{\mathrm{r}} \varphi
\end{aligned}
$$

Where $k_{f}$ and $k_{r}$ is the influence coefficient of roll camber and roll steer to the wheels respectively.

Under smaller sideslip angles and constant longitudinal velocity [8], $\beta=\frac{\mathrm{V}}{\mathrm{U}}$, the (4), (5) can be rearranged as:

$$
\begin{aligned}
& \alpha_{\mathrm{f}}=\delta_{\mathrm{f}}-\beta-\frac{\mathrm{l}_{\mathrm{fY}}}{\mathrm{u}}+\mathrm{k}_{\mathrm{f}} \varphi \\
& \alpha_{\mathrm{r}}=-\beta+\frac{1_{\mathrm{r} Y}}{\mathrm{u}}+\mathrm{k}_{\mathrm{r}} \varphi
\end{aligned}
$$

While the tires sideslip angles are small and load is vertical, the lateral forces and sideslip angles satisfy linear relation [8], so in (1) and (2),

The front tires lateral forces:

$$
\mathrm{F}_{\mathrm{yf}}=\mathrm{F}_{\mathrm{yfl}}+\mathrm{F}_{\mathrm{yfr}}=\mathrm{c}_{\mathrm{f}} \alpha_{\mathrm{f}}
$$

The rear tires lateral forces:

$$
\mathrm{F}_{\mathrm{yr}}=\mathrm{F}_{\mathrm{yrl}}+\mathrm{F}_{\mathrm{yrr}}=\mathrm{c}_{\mathrm{r}} \alpha_{\mathrm{r}}
$$

Selecting $\mathrm{x}=\left[\begin{array}{lllll}\beta & \gamma & \varphi & \dot{\varphi}\end{array}\right]^{\mathrm{T}}$ as system state variables, replacing the equations (1), (2) with (6)-(9), anda $\mathrm{y}_{\mathrm{y}}=\dot{\mathrm{V}}+\mathrm{U} \gamma$, the differential equations (1)-(3) change to state space forms as:

$$
\mathrm{Mx}=\mathrm{Ax}+\mathrm{B} \Delta \mathrm{M}+\mathrm{E}_{\mathrm{f}}
$$




$$
\begin{aligned}
& \text { In (10), } \quad \mathrm{M}=\left[\begin{array}{cccc}
\mathrm{mU} & 0 & 0 & \mathrm{~m}_{\mathrm{g}} \mathrm{h} \\
0 & \mathrm{I}_{z} & 0 & 0 \\
-\mathrm{m}_{\mathrm{g}} \mathrm{hU} & 0 & \mathrm{c}_{\varphi} & \left(\mathrm{I}_{\mathrm{x}}+\mathrm{mh}^{2}\right) \\
0 & 0 & 0 & 0
\end{array}\right] \\
& \mathrm{A}=\left[\begin{array}{cccc}
-2 \mathrm{c}_{\mathrm{f}}-2 \mathrm{c}_{\mathrm{T}} & \frac{2 \mathrm{c}_{\mathrm{r}} \mathrm{l}_{\mathrm{r}}-2 \mathrm{c}_{\mathrm{f}} \mathrm{l}_{\mathrm{f}}-\mathrm{mU}}{\mathrm{U}}-2 \mathrm{c}_{\mathrm{r}} \mathrm{k}_{\mathrm{r}}+2 \mathrm{c}_{\mathrm{f}} \mathrm{k}_{\mathrm{f}} & \mathrm{m}_{\mathrm{g}} \mathrm{h} \\
2 \mathrm{c}_{\mathrm{r}} \mathrm{l}_{\mathrm{r}}-2 \mathrm{c}_{\mathrm{f}} \mathrm{l}_{\mathrm{f}} & -\frac{2 \mathrm{c}_{\mathrm{f}} \mathrm{l}_{\mathrm{f}}{ }^{2}+2 \mathrm{c}_{\mathrm{r}} \mathrm{l}_{\mathrm{T}}^{2}}{\mathrm{U}} & 2 \mathrm{c}_{\mathrm{f}} \mathrm{l}_{\mathrm{f}} \mathrm{k}_{\mathrm{f}}-2 \mathrm{c}_{\mathrm{T}} \mathrm{l}_{\mathrm{r}} \mathrm{k}_{\mathrm{T}} & 0 \\
0 & -\mathrm{m}_{\mathrm{g}} \mathrm{hU} & \mathrm{m}_{\mathrm{g}} \mathrm{hg}-\mathrm{k}_{\mathrm{q}} & 0 \\
0 & 0 & 0 & 0
\end{array}\right] \\
& \mathrm{B}=\left[\begin{array}{llll}
0 & 1 & 0 & 0
\end{array}\right]^{\mathrm{T}} \\
& E=\left[\begin{array}{llll}
2 c_{\mathrm{f}} & 2 c_{\mathrm{f}} \mathrm{l}_{\mathrm{f}} & 0 & 0
\end{array}\right]^{\mathrm{T}}
\end{aligned}
$$

It can be seen from the above state equations that the suggested model contains not only static parameters related to vehicle structure but also have dynamic parameters relevant to vehicle traveling states, so the real vehicle rollover states can be obtained from the proposed model.

\section{The Control System based on Rollover Warning}

This paper presents a rollover warning control system shown in Figure. 2 which forms a closed-loop control system.

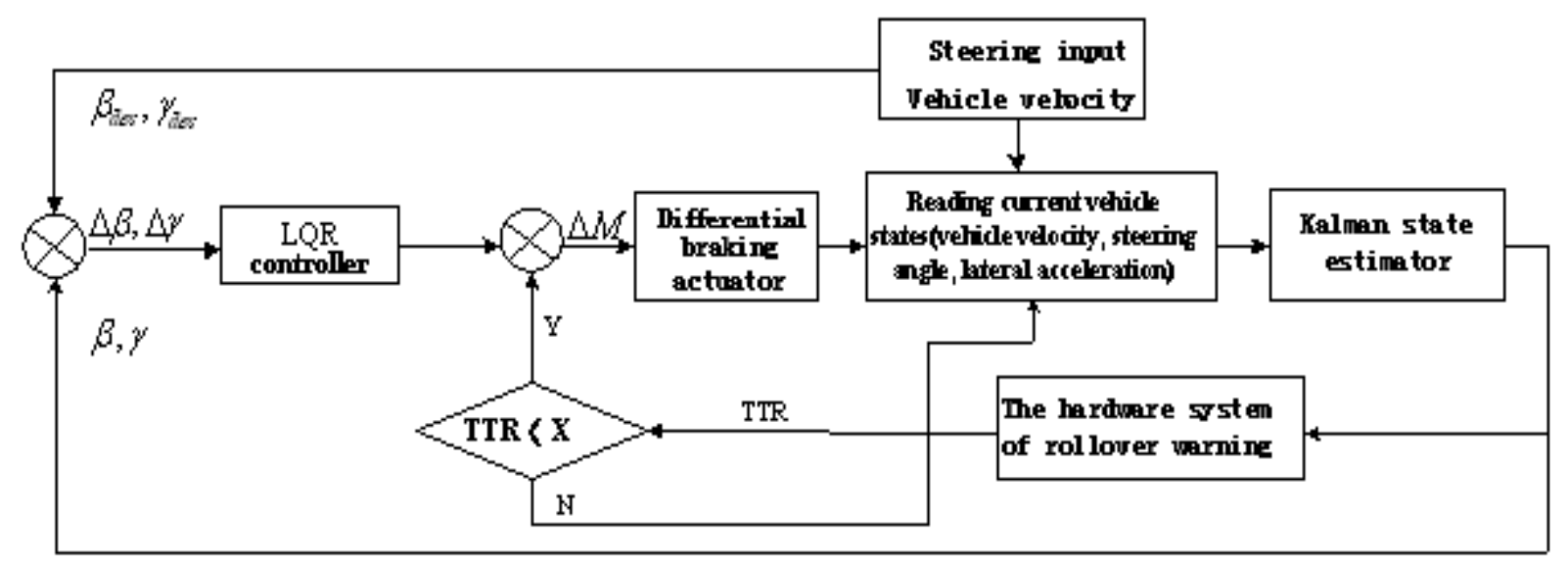

Fig. 2 the anti-rollover warning scheme based on hardware in the loop

The system inputs are steering angle and vehicle velocity, the vehicle information (including vehicle velocity, steering angle and lateral acceleration) are measured by vehicle sensors. The Kalman state estimator recurs the current vehicle states $(\beta \gamma \varphi \dot{\varphi})$ by sensor value which are used as the initial value of warning algorithm [9]. The rollover dynamic parameter LTR (lateral load transfer ratio) is given by the equation (15):

$$
|\mathrm{LTR}|=\left|\frac{2}{\mathrm{mgd}}\left[\mathrm{m}_{\mathrm{s}}\left(\mathrm{a}_{\mathrm{y}}-\mathrm{h} \ddot{\varphi}\right)(\mathrm{H}-\mathrm{h} \varphi)+\mathrm{k}_{\varphi} \varphi+\mathrm{c}_{\varphi} \dot{\varphi}\right]\right|
$$

According to the LTR, the time to rollover(TTR: being given the current moment input and the current states as initial conditions, the time needed when vehicle beginning to rollover or one of the wheels lifting off the ground) can be calculated .

The hardware system decides the TTR, if the TTR is smaller than the warning threshold X, which indicates the vehicle being about to rollover and the controller is triggered to act. The controller decides and obtains the additional yaw motion $\Delta \mathrm{M}$, the actuator imposes differential braking forces on relevant wheels. The output of the controller is the the additional yaw motion $\Delta \mathrm{M}$.

According to the current vehicle velocity and steering angle, the driver logically decides the desired vehicle sideslip angle $\beta_{\text {des }}$ and the desired vehicle yaw rate $\gamma_{\text {des }}, \Delta \beta$ and $\Delta \gamma$ is the difference between the measured state variables and their desired counterparts, the function of differential braking will be implemented to form a feedback compensator using the Linear Quadratic Regulator (LQR) technology. The controller obtains the optimum additional yaw motion $\Delta \mathrm{M}$ by the $\Delta \beta$ and $\Delta \gamma$. 


\section{The Simulations based on Rollover Warning Control System}

In this paper, the design of rollover warning controller is debugged and examined with real-time simulations on the vehicle simulator. The simulation system structure is shown in Figure.3, which is comprised of a host computer, an animator computer, a target computer, three monitors, NI real-time operating system, a driver operating interface, the communication link, the I/O interface board and the rollover warning hardware system. The core unit of hardware warning system is a signal chip microcomputer. The simulator allows the interactions between the driver and the controller such that the virtual vehicle is driven under the specified testing maneuvers [10].

In the system, the driver can manipulate the steering wheel to change $\delta_{f}$, the sensor signals can be sent to target computer by the $I / O$ card, the controller is designed in Lab View which is run in the target computer and the host computer and the NI real-time operating system is run in target computer also.

The real-time SUV model is developed in Car Sim which is run in host computer, the target computer transports the vehicle states to the SUV model of Car Sim in host computer through TCP/IP and the traveling SUV is shown in the three monitors by animator computer.

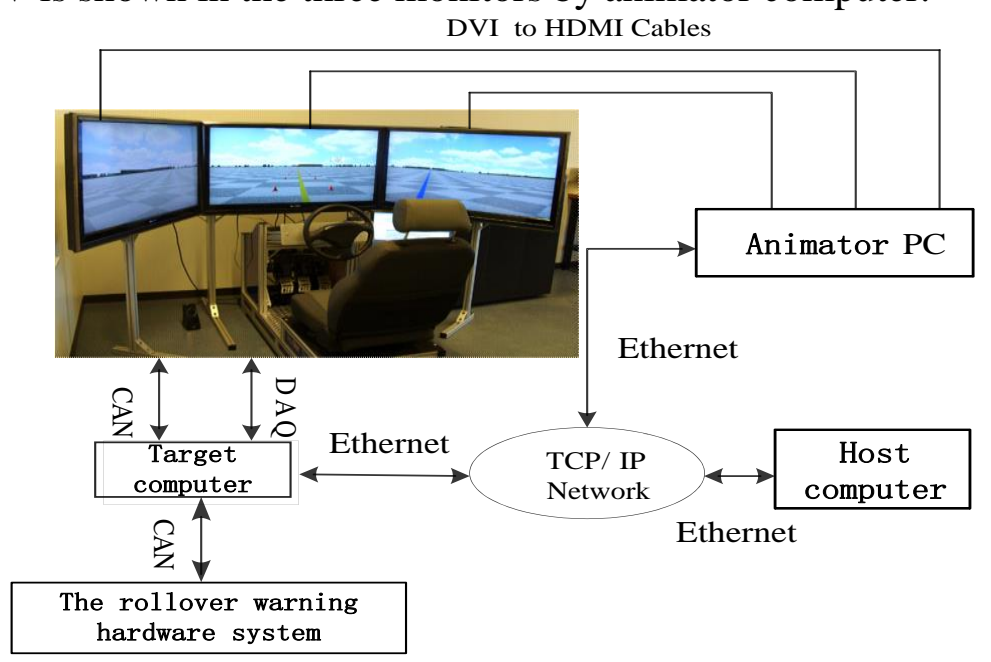

Fig. 3 The structure of simulation system

Meanwhile, the SUV state parameters are sent to the hardware unit by the CAN card and the hardware unit calculates the TTR. The target computer obtains the TTR and decides if to trigger the controller. If the controller is activated, it will give control instructions to all modules and hydraulic units, and the corresponding braking force will be produced on the wheels, finally, the traveling SUV is controlled.

The simulations use double lane change test which is easy to rollover to adjust and validate the controller performance, the important variables effecting the SUV stability such as sideslip angle and yaw rate, i.e. are analyzed and compared, the effects are also compared between TTR warning control and continuous control.

\subsection{Double Lane Change Simulation (The coefficient of friction $\boldsymbol{\mu}_{=0.5}$ )}

In this section, the anti-rollover warning simulations are conducted on the slippery roads (the coefficient of friction $\mu=0.5$ ) at the forward speed of the controlled vehicle being $90 \mathrm{kph}$ in the double lane change scenario.

The yaw rate and the sideslip angle are two important parameters reflecting vehicle traveling states where the yaw rate indicates the vehicle's turning ability and traveling traces, the sideslip angle shows the drifting performance of a vehicle.

Figure. 4 and Figure. 5 show the changes of yaw rate and sideslip angle if the rollover warning controls are acted and the comparison of TTR warning control and continuous control.

It can be seen that compared with the baselines, the control system makes the sideslip angle decrease remarkably and the corresponding yaw rate decline drastically in the danger corner. The TTR 
warning control can obtain nearly the same effect with the continuous control, it not only suppress yaw motion effectively but also prevent roll motion and lateral steering attitude.

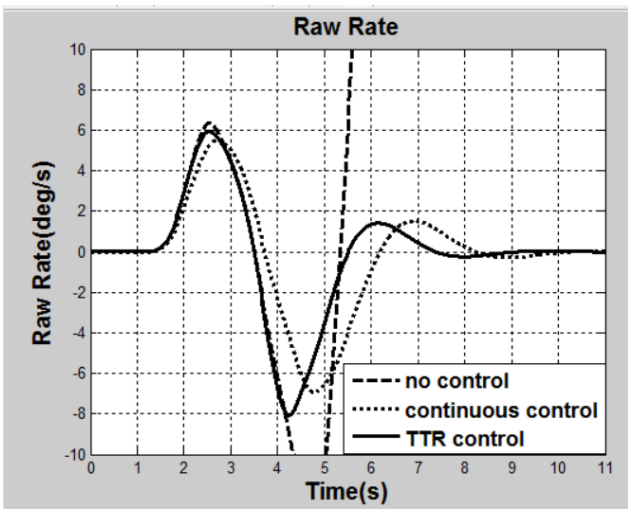

Fig. 4 the changes of yaw rate versus time

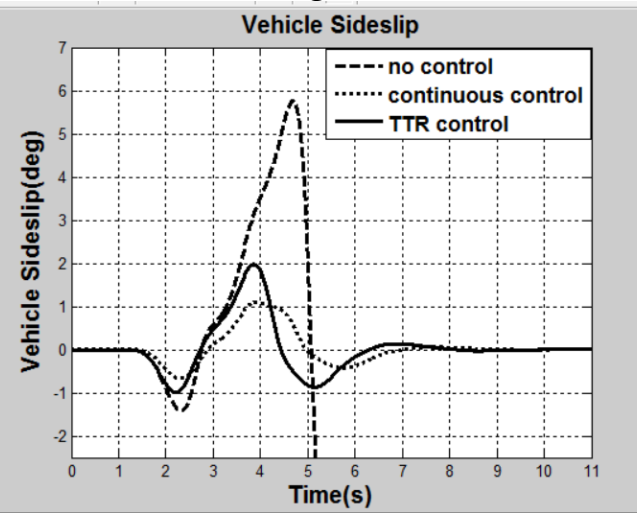

Fig. 5 the changes of sideslip angle versus time Figure.6 and Figure.7 illustrate the braking torques on front wheels.

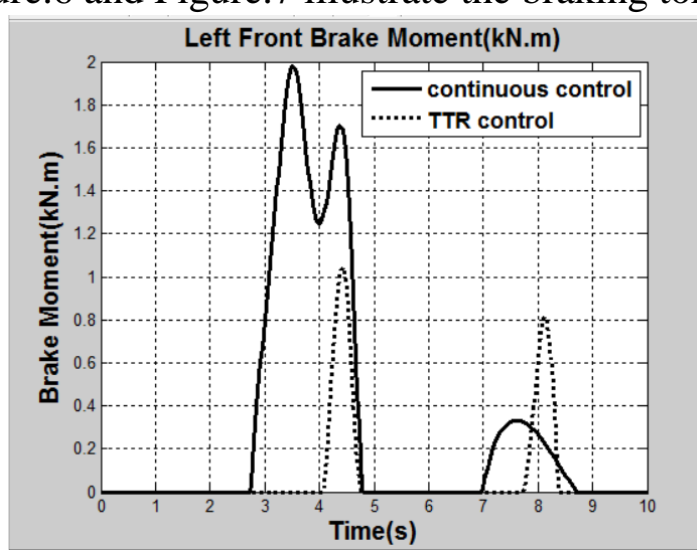

Fig. 6 the changes of left front brake moment

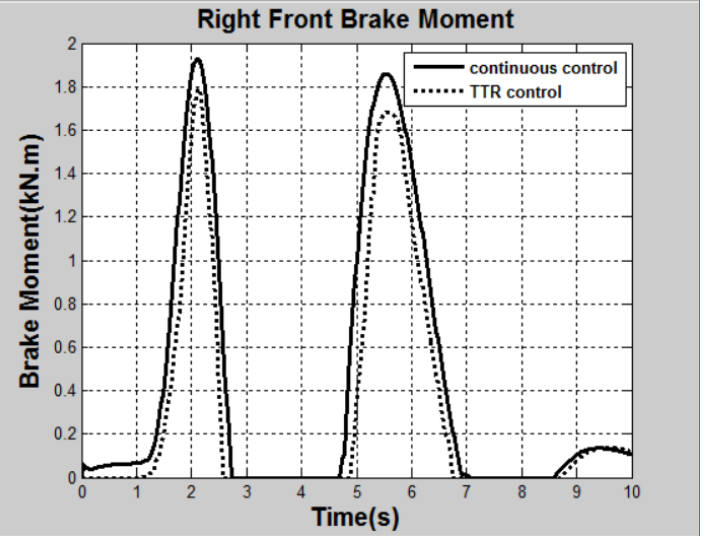

Fig. 7 the changes of right front brake moment

From Figure.6, the TTR warning control reduces the maximum control torque on left front wheel $1 \mathrm{kN} . \mathrm{m}$ and shortens the braking time 2 seconds compared with continuous control.

Similarly, Fig.7 shows the TTR warning control decrease the braking strength and time on right wheel a certain extent.

So, it is obvious that the TTR warning control reduces the braking strength and then relieve the driver pressure on travel.

\section{Conclusion}

This paper presents a design and validation method for anti-rollover warning controllers of SUVs using hardware-in-the-loop real-time simulations. The results indicate that in the double lane change scenario, the proposed rollover warning control system can enhance the anti-rollover performance of the vehicle and prevent rollover accidents effectively. It can be further showed that this rollover warning algorithm is reliable and effective in all kinds of driving cycles. The next research will further optimize the anti-rollover hardware circuits and improve the accuracy of TTR.

\section{Acknowledgments}

Financial support for this research is provided by The Natural Science Foundation of Hubei Province (No.2014CFB477) and Hubei Key Laboratory of Low Dimensional Optoelectronic Material and Devices (No.HLOM142011). 


\section{References}

[1]. S. Pan, X. Zhang and N. Wang. The Research of anti-rollover Control based on Differential Braking, Computer Simulation,vol.30 (2013) No.6, p.174-177.

[2]. O. Barbarisi, G.Palmieri and S. Scala. LTV-MPC for yaw rate control and side slip control with dynamically constrained differential braking, European Journal of Control, vol.15 (2009) No.12, p.468-479.

[3]. D.Sun, F.Lan and J. Chen. Control Algorithm of Electric Vehicle in Coasting Mode Based on Driving Feeling. Chinese Journal of Mechanical Engineering. vol.28 (2015) No.3. p. 479-486.

[4]. L.Song and Y.He. The Design of SUV Anti Rollover Controller Based on Driver-in-the-Loop Real-Time Simulations. Computer Engineering and Applications, vol.52 (2016) No.9, p. 223-227.

[5]. J.Huang, K.Liu and Y. Xiong. The Current Situation Research on Vehicle Rollover Warning and Control System. Lightweigh Car Technology. vol.39 (2011) No.1, p.16-19.

[6]. Z.Jin, H.Zhang and C. Ma. The Research on Sport Utility Vehicles Rollover Warning System. The Sensor and the Microsystem. vol.31 (2012) No.9, p.32--35.

[7]. Z.Long. the Rollover Control Research of Semitrailer Train on TruckSim. Master' Thesis, Guangxi University, China, 2014.

[8]. Z.Yu. Automobile Theory, 4rd ed. Beijing: China Machine Press, 2007, p.114-118.

[9]. Z.Zhao , H.Chen and J. Yang. Estimation of the vehicle speed in the driving mode for a hybrid electric car based on an unscented Kalman filter. Proceedings of the Institution of Mechanical Engineers Part D-journal of Automobile Engineering, vol.229 (2015) No.4, p. 437-456.

[10]. X. Ding, Y.He. Application of Driver-in-the-Loop Real-Time Simulations to the Design of SUV Differential Braking Controllers. ICIRA 2012, Part I, LNAI 7506, p. 121-131. 